NOTE

\title{
Concentration of carp edema virus (CEV) DNA in koi tissues affected by koi sleepy disease (KSD)
}

\author{
Mikolaj Adamek ${ }^{1}$, Verena Jung-Schroers ${ }^{1}$, John Hellmann ${ }^{1,6}$, Felix Teitge ${ }^{1}$, \\ Sven Michael Bergmann ${ }^{2}$, Martin Runge ${ }^{3}$, Dirk Willem Kleingeld ${ }^{4}$, Keith Way ${ }^{5}$, \\ David Michael Stone ${ }^{5}$, Dieter Steinhagen ${ }^{1, *}$
}

\author{
${ }^{1}$ Fish Disease Research Unit, University of Veterinary Medicine, Hannover, 30559 Germany \\ ${ }^{2}$ Institute of Infectology, Federal Research Institute for Animal Health, Friedrich-Loeffler-Institut, \\ 17493 (postal code 9) Greifswald, Germany \\ ${ }^{3}$ Food and Veterinary Institute, Lower Saxony State Office for Consumer Protection and Food Safety, \\ 30173 Hannover, Germany
}

${ }^{4}$ Veterinary Task-Force, Lower Saxony State Office for Consumer Protection and Food Safety, 30173 Hannover, Germany

${ }^{5}$ Centre for Environment, Fisheries and Aquaculture Science (CEFAS), Weymouth, Dorset, DT4 7TY, UK

${ }^{6}$ Present address: Landesamt für Natur, Umwelt und Verbraucherschutz Nordrhein-Westfalen (LANUV), Fisheries Ecology, Heinsberger Str. 53, 57399 Kirchhundem-Albaum, Germany

\begin{abstract}
Carp edema virus (CEV), the causative agent of 'koi sleepy disease' (KSD), appears to be spreading worldwide and to be responsible for losses in koi, ornamental varieties of the common carp Cyprinus carpio. Clinical signs of KSD include lethargic behaviour, swollen gills, sunken eyes and skin alterations and can easily be mistaken for other diseases, such as infection with cyprinid herpesvirus 3 (CyHV-3). To improve the future diagnosis of CEV infection and to provide a tool to better explore the relationship between viral load and clinical disease, we developed a specific quantitative PCR (qPCR) for strains of the virus known to infect koi carp. In samples from several clinically affected koi, CEV-specific DNA was present in a range from 1 to 2046000 copies, with a mean of 129982 copies and a median of 45 copies per $250 \mathrm{ng}$ of isolated DNA, but virus DNA could not be detected in all clinically affected koi. A comparison of the newly developed qPCR, which is based on a dual-labelled probe, to an existing end-point PCR procedure revealed higher specificity and sensitivity of the qPCR and demonstrated that the new protocol could improve CEV detection in koi. In addition to improved diagnosis, the newly developed qPCR test would be a useful research tool. For example, studies on the pathobiology of CEV could employ controlled infection experiments in which the development of clinical signs could be examined in parallel with a quantitative determination of virus load.
\end{abstract}

KEY WORDS: Carp edema virus $\cdot$ Koi sleepy disease $\cdot$ Real-time PCR $\cdot$ Common carp $\cdot$ Koi Cyprinus carpio

\section{INTRODUCTION}

Viral infections of fish may induce severe diseases associated with high morbidity and mortality, and the global trade of healthy-appearing infected individuals (subclinical carriers) of susceptible species has great potential for spreading such infections. This

${ }^{*}$ Corresponding author:

dieter.steinhagen@tiho-hannover.de was evident in infections with cyprinid herpesvirus 3 (CyHV-3), also known as koi herpesvirus (KHV). CyHV-3 is a highly contagious pathogen which infects common carp Cyprinus carpio as well as koi, its ornamental varieties, and can result in up to $100 \%$ mortality in affected populations (Rakus et al. 2013). Infections first observed in koi (Hedrick et al. 2000)

() The authors 2016. Open Access under Creative Commons by Attribution Licence. Use, distribution and reproduction are unrestricted. Authors and original publication must be credited. 
were globally spread by uncontrolled trade with apparently healthy but subclinically infected koi (Haenen \& Hedrick 2006), and later also affected the carp aquaculture industry resulting in heavy losses (Bocklisch et al. 2006). For this reason, CyHV-3 became the focus of surveillance programmes globally. Unfortunately, delayed disease control measures could not prevent the global distribution of this disease, and now CyHV-3 is considered to be the major viral pathogen in carp and seriously challenges the trade of ornamental koi and carp production worldwide (Haenen \& Hedrick 2006, Rakus et al. 2013).

Carp edema virus (CEV), a pox virus, is another virus that infects carp, which also might have the potential to become a significant threat. CEV has been known to cause 'koi sleepy disease' (KSD) in ornamental carp varieties (koi) in Japan since the 1970s. For a long time, the occurrence of this disease appeared to be limited to Japan (Oyamatsu et al. 1997a, Miyazaki et al. 2005). However, the situation changed in 2013 when the first report of koi affected by KSD was published based on samples collected in the UK (Way \& Stone 2013). Shortly afterwards, the virus was also detected in the Netherlands (Haenen et al. 2014) and Austria (Lewisch et al. 2015). In spring 2014, a clinical outbreak of KSD was diagnosed in several koi populations in Germany (JungSchroers et al. 2015).

With mortalities of up to $80 \%$ in populations of naïve juvenile koi in Japan (Oyamatsu et al. 1997a), KSD has the potential to seriously threaten koi populations. A treatment regime using salt baths for a prolonged period of time limited losses for Japanese koi farmers (Miyazaki et al. 2005) and led the koi industry to the assumption that KSD could easily be controlled. However, the recent disease outbreaks of clinical KSD in European koi populations indicate the need for further studies on this infection.

The most common clinical signs of KSD are lethargic behaviour (hence the name 'koi sleepy disease'), swollen gills (Miyazaki et al. 2005), enophthalmos and haemorrhages often around the mouth and at the base of the fins (Oyamatsu et al. 1997a, Way \& Stone 2013). With this set of clinical signs, the disease can easily be mistaken for other diseases, for instance koi herpesvirus disease (KHVD). Therefore, a reliable detection method for CEV for inclusion into routine disease surveillance programmes in koi is required.

Currently, the detection of CEV in affected individuals is based on an end-point PCR coupled with a nested PCR, developed by Oyamatsu et al. (1997b). This protocol, however, did not confirm the presence of CEV DNA in all individuals from clinical cases in Germany, which displayed clinical signs of a disease and which were confirmed negative for infections with carp herpesviruses, bacteria or parasites (JungSchroers et al. 2015). In some of the clinically affected individuals, a CEV infection could only be confirmed with the nested PCR, which indicated a low virus load and raised questions concerning the clinical findings. We therefore developed a real-time PCR based on a dual labelled probe that allowed us to quantify the viral load in the examined samples, which in turn would aid in the evaluation of the significance of the virus to the etiology of the disease and will enable investigations into the infection kinetics of the virus in affected populations.

\section{MATERIALS AND METHODS}

\section{Sample collection}

Gill tissue, and in some cases skin samples, were collected from 3 different groups of fish. Gill samples were collected from affected regions of the first gill arch on the left side of the body. In koi smaller than $5 \mathrm{~cm}$ body size, tissue from all 4 gill arches of the left body side was collected. Skin samples were collected from the ventral part of the left side of the body. One group comprised samples from a total of 33 koi originating from 21 fish tanks or ponds of wholesalers or hobbyists in Lower Saxony, Germany (Table 1). Of these koi, 26 were sampled when moribund or recently deceased. These fish presented typical clinical signs of an infection with an epitheliotropic virus, including lesions and necrosis of the gills and skin. In addition, 7 subclinical individuals were sampled from the same ponds/tanks where the disease was detected previously but the sampled koi did not show any clinical signs (Table 1). Observations on 11 of these koi formed the basis of a previous communication on the first detection of CEV in Germany (Jung-Schroers et al. 2015). In all cases, no bacterial or parasitic pathogens could be confirmed as the cause of morbidity or mortality using methods as described by JungSchroers et al. (2015). All koi were diagnosed as CyHV-3 negative using quantitative PCR (qPCR) following previous methods (Gilad et al. 2004, JungSchroers et al. 2015). A second group of samples consisted of 12 gill pools (gill tissue from $2 \mathrm{koi} \mathrm{pool}^{-1}$ ) collected from 12 koi batches with subclinical individuals which were imported from Asia to Germany shortly beforehand. A third group of samples contained gill tissue from 3 moribund common carp indi- 
Table 1. Koi Cyprinus carpio examined for the presence of carp edema virus (CEV) DNA by real-time and end-point PCRs, quantitative determination of the CEV load in positive samples by qPCR and a comparison of qPCR results to the end-point PCR protocol established by Oyamatsu et al. (1997b). The copy number of CEV-specific DNA per $250 \mathrm{ng}$ of DNA determined by qPCR is given. +: positive signal in the end-point $\mathrm{PCR}_{;}-$: negative $\mathrm{PCR}$ result; na: sample was not analysed

\begin{tabular}{|c|c|c|c|c|c|c|}
\hline $\begin{array}{l}\text { Fish } \\
\text { ID }\end{array}$ & $\begin{array}{l}\text { Pond/ } \\
\text { tank ID }\end{array}$ & $\begin{array}{l}\text { Clinical signs } \\
\text { incl. death }\end{array}$ & $\begin{array}{l}\text { qPCR } \\
\text { Gill }\end{array}$ & $\begin{array}{c}\text { CEV_F1/R1 } \\
\text { Gill }\end{array}$ & $\begin{array}{c}\text { Nested CEV_F2/R2 } \\
\text { Gill }\end{array}$ & $\begin{array}{l}\text { qPCR } \\
\text { Skin }\end{array}$ \\
\hline 1 & 1 & Yes & 2046000 & + & na & na \\
\hline 2 & 1 & Yes & 16220 & + & na & na \\
\hline 3 & 1 & No & - & - & - & na \\
\hline 4 & 1 & No & - & - & - & na \\
\hline 5 & 2 & Yes & - & - & - & na \\
\hline 6 & 3 & Yes & - & - & - & na \\
\hline 7 & 3 & No & - & - & - & na \\
\hline 8 & 4 & Yes & 11 & + & na & na \\
\hline 9 & 4 & Yes & 2 & - & - & na \\
\hline 10 & 4 & Yes & 45 & + & na & na \\
\hline 11 & 5 & Yes & 34 & + & na & na \\
\hline 12 & 6 & Yes & - & - & - & na \\
\hline 13 & 6 & No & - & - & - & na \\
\hline 14 & 4 & Yes & 2 & - & + & na \\
\hline 15 & 7 & Yes & 132800 & + & na & na \\
\hline 16 & 8 & Yes & - & - & - & na \\
\hline 17 & 8 & No & - & - & - & na \\
\hline 18 & 9 & Yes & 241700 & + & na & 4824 \\
\hline 19 & 10 & No & - & - & - & na \\
\hline 20 & 10 & No & - & - & - & na \\
\hline 21 & 11 & Yes & 2 & - & + & na \\
\hline 22 & 11 & Yes & - & - & - & na \\
\hline 23 & 12 & Yes & - & - & - & na \\
\hline 24 & 13 & Yes & - & - & - & na \\
\hline 25 & 14 & Yes & 59 & + & na & na \\
\hline 26 & 14 & Yes & 3402 & + & na & na \\
\hline 27 & 15 & Yes & 3 & - & - & na \\
\hline 28 & 16 & Yes & 387 & + & na & - \\
\hline 29 & 17 & Yes & 7 & + & na & - \\
\hline 30 & 18 & Yes & 1 & - & - & - \\
\hline 31 & 19 & Yes & 1 & - & - & - \\
\hline 32 & 20 & Yes & 23070 & + & na & 2066 \\
\hline 33 & 21 & Yes & 5910 & + & na & na \\
\hline
\end{tabular}

viduals diagnosed to be positive for CEV in early 2015 using an unpublished set of primers designed by the World Organisation for Animal Health (OIE) reference laboratory at the Centre for Environment, Fisheries and Aquaculture Science (CEFAS, Weymouth, UK).

\section{DNA isolation and end-point PCR analysis}

DNA was isolated after mechanical lysis of $\sim 25 \mathrm{mg}$ tissue by Tissue Lyser II (Qiagen), using the QIAamp DNA Mini Kit (Qiagen) according to the manufacturer's manual. After isolation, the DNA concentration was measured with a Nanodrop ND-1000 (Peqlab) spectrophotometer, and the samples were diluted with PCR-grade water (Thermo Fisher Scientific) to a concentration of $50 \mathrm{ng}^{-1}$ and stored at $-80^{\circ} \mathrm{C}$. Additionally, 4 DNA samples $(2$ samples positive for cyprinid herpesvirus 1 [CyHV-1] and 2 samples positive for CyHV-3) were collected from previous diagnostic samples and included in the study to test for specificity and cross-reactivity of the newly developed qPCR.

The end-point PCR developed by Oyamatsu et al. (1997b) was initially used for the detection of CEV-specific genome sequences (fragment encoding for part of P4a core protein) in the tissue samples. The end-point PCR was performed using a KAPA2G Robust Hot Start PCR kit (Peqlab), the primers CEV_F1/CEV_R1 and CEV F2/CEV_R2 (Table 2) and $250 \mathrm{ng}$ of DNA. The thermal profile used included an initial denaturation step at $95^{\circ} \mathrm{C}$ for $3 \mathrm{~min}$ followed by 40 cycles at $95^{\circ} \mathrm{C}$ for $30 \mathrm{~s}, 55^{\circ} \mathrm{C}$ for $30 \mathrm{~s}$ and $72^{\circ} \mathrm{C}$ for $30 \mathrm{~s}$, and a final extension step at $72^{\circ} \mathrm{C}$ for 7 min using a Labcycler (Sensoquest). PCR products were ligated into the pGEM-T Easy vector (Promega) and propagated in JM109 competent Escherichia coli bacteria (Promega) following the manufacturer's instructions. Plasmids were isolated with the GeneJET Plasmid Miniprep Kit (Fermentas) following the manufacturer's instructions, and inserts were sequenced (LGC Genomics) using T7 and SP6 promoter sequencing primers (Table 2). Obtained sequences were compared to sequences published by Oyamatsu (1996) and a sequence obtained from the OIE reference laboratory at CEFAS.

\section{Quantitative real-time PCR}

In order to quantify the virus load in individuals found to be CEV positive, a quantitative real-time PCR was developed on the basis of the previously obtained nucleotide sequence (GenBank ID: KM283182) amplified from samples of CEV-positive koi using the primer set published by Oyamatsu et al. (1997b) and using additional sequences supplied by 
Table 2. Sequences of primers and probes used in this work. Primers were used as indicated by letters, where E: end-point PCR; P: amplification of gene fragments for plasmid-based quantification; Q: qPCR analyses; S: sequencing

\begin{tabular}{|llccc|}
\hline $\begin{array}{l}\text { Primer/ } \\
\text { probe }\end{array}$ & Sequence $\left(5^{\prime}-3^{\prime}\right)$ & $\begin{array}{c}\text { GenBank } \\
\text { ID }\end{array}$ & Use & Reference \\
\hline CEV_F1 & GCT GTT GCA ACC ATT TGA GA & - & E, P & Oyamatsu et al. (1997b) \\
CEV_R1 & TGC AGG TTG CTC CTA ATC CT & - & E, P & Oyamatsu et al. (1997b) \\
CEV_F2 & GCT GCT GCA CTT TTA GGA GG & - & E & Oyamatsu et al. (1997b) \\
CEV_R2 & TGC AAG TTA TTT CGA TGC CA & - & E & Oyamatsu et al. (1997b) \\
CEV_qF1 & TTT AGG AGG ACA AGT AAA GTT ACC A & KM283182 & Q & - \\
CEV_qR1 & GCA AGT TAT TTC GAT GCC AAC C & KM283182 & Q & - \\
CEV_probe1 & [FAM]-CCA GCT CCT ACA AGG AAA GCA ATT GA-[BHQ] & KM283182 & Q & - \\
T7 & TAA TAC GAC TCA CTA TAG GG & - & S & Promega \\
SP6 & TAT TTA GGT GAC ACT ATA G & - & S & Promega \\
\hline
\end{tabular}

the OIE reference laboratory at CEFAS (Fig. S1 in the Supplement at www.int-res.com/articles/suppl/d119 p245_supp.pdf). Primers and probe for the qPCR were designed with the IDT RealTime qPCR tool (http:// eu.idtdna.com/scitools/Applications/RealTimePCR). Primer and probe concentrations were selected during a reaction optimisation process, with combinations of 3 primer concentrations $(50,300,900 \mathrm{nM})$ and 6 probe concentrations $(50,100,150,200,250$, $300 \mathrm{nM}$ ) being tested. The final diagnostic reaction mix contained 1× Master Mix (Maxima Probe qPCR Mastermix, Thermo Fisher Scientific), $900 \mathrm{nM}$ of each primer, $300 \mathrm{nM}$ of the probe (sequences in Table 2) and $250 \mathrm{ng}$ of template DNA. For quantification of CEV load, DNA standards based on supercoiled recombinant plasmid DNA (recDNA) were generated using 1 of the above mentioned plasmids containing the PCR product amplified with the CEV_F1/CEV_R1 primers. The number of plasmids was calculated from the DNA concentration of the plasmid preparation (absorbance at $260 \mathrm{~nm}$ ) and the molecular weight of DNA. A standard from $10^{0}$ to $10^{7}$ recDNA plasmids was prepared by 10 -fold dilution with PCR-grade water and used for a quantification of virus DNA copy number. The qPCR was performed using a Stratagene Mx 3005P thermocycler (Agilent) with a thermal profile including an initial denaturation step at $95^{\circ} \mathrm{C}$ for $10 \mathrm{~min}$, followed by 40 cycles at $95^{\circ} \mathrm{C}$ for $30 \mathrm{~s}$ and $60^{\circ} \mathrm{C}$ for $30 \mathrm{~s}$. All samples were run in duplicate. Fluorescence data were analysed using the Stratagene MxPro Software (Agilent) and exported to Microsoft Excel. The results are presented as the total number of virus copies per $250 \mathrm{ng}$ of DNA. From a standard curve constructed from $10^{0}$ to $10^{7}$ copies of recDNA plasmids of $\mathrm{CEV}$ and from a serially (10-fold) diluted CEV-positive sample as a template, we concluded that the limit for a reliable detection of CEV using the new qPCR is lower than
10 copies of CEV-specific DNA, with 1 copy of the viral genome being detectable. With the standard, the qPCR gave the amplification curve $y=-3.2499 x+$ 41.706 with a correlation $\mathrm{R}^{2}=0.9988$ and efficiency of 103.1\% (range 99.3-105. $1 \%$, Fig. 1).

To further ensure the reliability of the qPCR protocol, selected CEV-positive samples were examined in 3 independent qPCR runs. The standard deviation (SD) of the cycle threshold (Ct) values achieved in the 3 replications was below 1 in most of the samples. Only 1 sample which was bearing 1 copy of the virus showed a higher SD of 1.5 (Table S1 in the Supplement).

When DNA from a diagnostic sample was diluted 10-fold, a linear amplification curve was achieved for at least 5 orders of dilution (Table S2 in the Supplement). The specificity of the newly developed qPCR was confirmed by analysing samples from fish infected with CyHV-1 and CyHV-3 viruses. No fluorescent signal was detected in these samples.

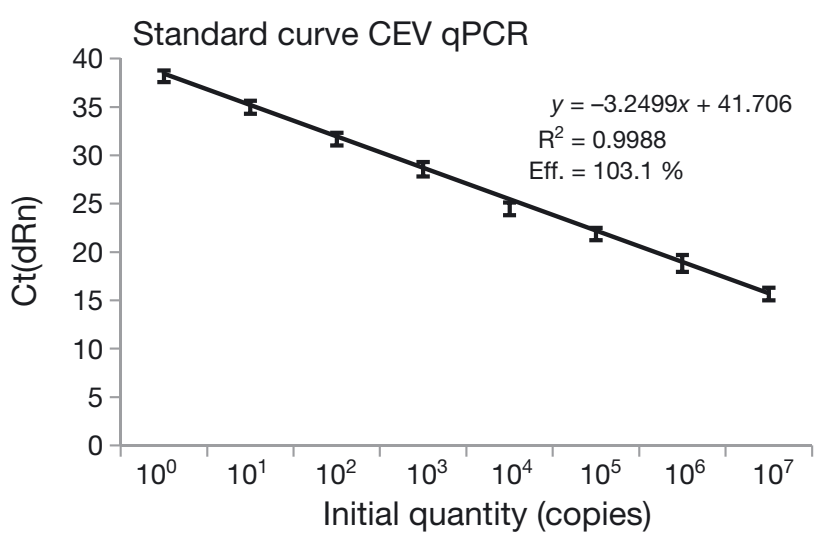

Fig. 1. Standard curve for $10^{0}$ to $10^{7}$ copies of supercoiled recombinant plasmid DNA used in qPCR. Standard curve represents mean $\pm \mathrm{SD}$ from $\mathrm{n}=3$ replicates. $\mathrm{Ct}(\mathrm{dRn})$ : cycle threshold based on delta (change) of normalised fluorescence; Eff.: efficiency 
The end-point PCR designed by Oyamatsu et al. (1997b) was included in all analyses to compare the sensitivity of the new $\mathrm{qPCR}$ in routine CEV diagnostics.

\section{RESULTS}

\section{Virus load in gills of clinically affected koi}

Screening of gill samples from 33 koi from the disease outbreak in 2014 by means of the end-point PCR developed by Oyamatsu et al. (1997b) confirmed the presence of CEV DNA in 15 fish out of 26 clinically affected specimens (Table 1). Surprisingly, not all clinically affected individuals were positive for $\mathrm{CEV}$, and in 2 clinically affected koi, the presence of CEV DNA could be detected only in the second round (nested) PCR. The results from this end-point PCR indicated a wide range of the virus load in affected individuals but did not allow further quantification. For determination of the virus load, all samples were subsequently analysed by means of the new qPCR. In this analysis, the presence of CEV DNA could be detected in 19 out of the 26 clinically affected koi with a virus load ranging from 1 to 2046000 copies with a mean of 129982 and a median of 45 copies per $250 \mathrm{ng}$ of isolated DNA (Table 1). In $7 \mathrm{koi}$, the virus load was as high as 1000 copies per 250 ng of DNA, and in another 7 individuals, the virus load was below 10 copies per $250 \mathrm{ng}$ of DNA. To exclude potential false negative results, additional DNA extractions were performed from samples taken from the clinically affected but CEV-negative koi. Again, the analysis of these samples by means of both PCR protocols (end-point and qPCR) gave negative results.

\section{CEV detection in subclinical koi}

In gill samples from subclinical individuals collected from the same tanks as clinically affected koi (Tanks 1, 3, 6 and 8 in Table 1) at a later time point, CEV DNA could not be detected during the 2014 event. In contrast, the presence of CEV could be found in gill tissues of koi from 8 out of 12 koi batches examined shortly after being imported from Asia to Germany. The koi from all of these shipments appeared healthy even though in 2 batches the koi harboured more than 1000 copies of the CEV genome per $250 \mathrm{ng}$ of DNA (Table 3).
Table 3. Koi Cyprinus carpio batches exported from Asia to Germany and examined for the presence of carp edema virus (CEV). The CEV load is presented as the number of copies of the CEV genome per $250 \mathrm{ng}$ of DNA isolated from gills pooled from 2 fish. nd: CEV-specific DNA not detected

\begin{tabular}{|cc|}
\hline Batch number & CEV load \\
\hline B1 & 9 \\
B2 & 2 \\
B3 & 42 \\
B4 & nd \\
B5 & 2 \\
B6 & nd \\
B7 & 27 \\
B8 & 11840 \\
B9 & nd \\
B10 & 3 \\
B11 & nd \\
B12 & 4639 \\
\hline
\end{tabular}

\section{Comparison of skin and gill samples from koi}

Skin and gill samples were collected from 6 koi individuals for a comparison of the virus load between the 2 organs. Virus DNA could be detected in 6 of the gill samples and in only 2 skin samples with 11 or 50 times lower virus load than in the gills (Table 1).

\section{CEV detection in carp samples by the new qPCR}

When gill samples from clinically affected carp were analysed for the presence of CEV-specific DNA, both the end-point PCR designed by Oyamatsu et al. (1997b) and the new pPCR gave negative results.

\section{DISCUSSION}

For a long time, clinical outbreaks of KSD appeared to be restricted to Japanese koi farms where losses due to KSD could be controlled by a treatment using prolonged salt baths (Oyamatsu et al. 1997b, Miyazaki et al. 2005). Therefore, when koi populations in Europe or North America were found sick with clinical signs including gill and skin changes, depressed behaviour and sunken eyes, fish health professionals often assumed the koi were suffering from a disease caused by infection with CyHV3 , and when diagnostic tests for the presence of CyHV-3 gave negative results, the presence of undetected CyHV-3 variants was discussed (Engelsma et 
al. 2013). Recent reports of a CEV infection from such individuals raise the question of the epidemiological importance of this pathogen. When examined by qPCR, a high virus load could be detected in 7 clinically affected koi, suggesting that the CEV infection might be responsible for the observed clinical signs of disease in these fish. Surprisingly, in gill samples from 8 clinically affected koi, only low copy numbers of CEV-specific DNA were found, and samples from another 7 clinically affected koi gave negative results. Information on the development of virus load in koi with CEV infection is scarce. Miyazaki et al. (2005) reported the presence of numerous immature viral particles in enlarged respiratory branchial cells during the initial phase of infection, while mature virions were observed in hypertrophied cells of the branchial epithelium and not in cells of the basal region of the clubbed gill filament (Miyazaki et al. 2005). A study which correlates the sequential appearance of histopathological changes with a quantitative assessment of the virus load during the course of infection has not been performed to date. The observation that koi kept in water supplemented with $0.5 \%$ salt developed gill pathology but were not suffering from clinical KSD (Miyazaki et al. 2005) suggests that clinical KSD is mostly related to a disturbance of the osmotic balance in koi due to destruction of the branchial osmotic barrier when CEVinfected gill epithelium cells deteriorate. Hence, in koi suffering from clinical KSD, the CEV load might already have declined. At present, the large differences in virus load in the gill samples from clinically affected koi are difficult to interpret and further infection experiments with CEV are needed, especially to determine the virulence potential of this virus and the virus load which is associated with disease signs and death.

It is unclear whether CEV might persist in subclinical koi from KSD-affected populations. In the present study, CEV could not be detected in gill samples from such fish during the 2014 event. However, some koi from recently imported populations harboured high copy numbers of CEV-specific DNA in gills without developing signs of a disease (Table 3). This might suggest a stress-related reactivation of a persistent CEV infection, as is also suspected in fowlpox infections (Lachish et al. 2012). This result may show a potential dispersal route of $\mathrm{CEV}$.

In previous studies (Ono et al. 1986, Oyamatsu et al. 1997a, Miyazaki et al. 2005), CEV was mainly found in gills of affected koi and only occasionally in skin, liver or spleen (Amita et al. 2002). This could be confirmed in the present study, where CEV was detected more often in gills than in skin. Hence, gills were a more reliable tissue for CEV detection than skin or other tissues.

In addition to the quantification of virus-specific DNA copies, the new qPCR gives a significant advantage over the already established end-point PCR for the detection of a CEV infection in koi because it has a noticeably higher sensitivity. Using the protocol for the first round end-point PCR from Oyamatsu et al. (1997b), 13 out of 33 samples were CEV positive, while 6 samples with a virus load of 1 to 3 copies per $250 \mathrm{ng}$ of DNA detected by the new qPCR remained negative. When Oyamatsu's nested end-point PCR was applied (Oyamatsu et al. 1997b), a positive signal was observed in 2 additional samples (Table 1). Despite the relatively good sensitivity of the nested endpoint PCR, the procedure gave false negative results for 4 samples, and it took 3 times longer to obtain data compared to the newly developed qPCR. Furthermore, as indicated by other authors (Way \& Stone 2013), the nested PCR produced non-specific products (Fig. S2 in the Supplement) which can confound interpretation of the results.

Interestingly, a carp edema virus was also detected in common carp displaying clinical signs and mortality in the UK in March 2012 (Way \& Stone 2013), and recently CEV was also diagnosed from diseased common carp in Austria (Lewisch et al. 2015) followed by 2 further clinical cases in common carp in Germany in 2015. Sequencing of the PCR amplicons from common carp and koi isolates revealed significant (over 6\%) differences in DNA sequences, suggesting the existence of 2 lineages of CEV: 1 from koi and 1 from common carp (Way \& Stone 2013). As predicted from an in silico analysis of sequences (Fig. S1), the newly designed qPCR is specific only for the koi lineage of CEV, because samples from common carp gave negative results. In these samples, the end-point PCR by Oyamatsu et al. (1997b) was also not capable of detecting CEV DNA.

In conclusion, the analysis of gill samples from koi affected by KSD by means of a new qPCR revealed a large difference in CEV load. For a correlation of disease signs to the virus load determined in gills of affected individuals, controlled infection experiments are needed in which the development of clinical signs is examined in parallel to quantitative determination of virus load. In such experiments, our newly developed qPCR could be useful. In addition, this qPCR was found to be a specific, more sensitive, faster and more reliable tool for the detection of CEV in koi compared to the previously used end-point PCR designed by Oyamatsu et al. (1997b) and could 
improve disease diagnosis in koi suffering from clinical signs such as lethargy and gill necrosis, particularly since fish health professionals might not be aware of the current presence of CEV infection in European koi populations. As a diagnostic tool, the qPCR will also be very useful in the regulation of the currently largely unsurveyed global trade of koi, thereby preventing or limiting the spread of $\mathrm{CEV}$ into natural or aquaculture populations of common carp in continental Europe. Finally, the confirmation of high virus loads in dead fish suggests that the CEV infection might have the potential to be an emerging disease and could result in similar economic consequences as those seen with CyHV-3-infections, which has harmed the financial status of many carp farms around the world.

Acknowledgements. We thank the reviewers and the editor for their valuable suggestions on the manuscript.

\section{LITERATURE CITED}

Amita K, Oe M, Matoyama H, Yamaguchi N, Fukuda H (2002) A survey of koi herpesvirus and carp edema virus in colorcarp cultured in Niigata Prefecture, Japan. Fish Pathol 37:197-198

Bocklisch H, Landsiedel U, Dresenkamp B (2006) Outbreak of koi herpesvirus infection in carps in northern Thuringia. Tieraerztl Prax G Grosstiere Nutztiere 34: 121-125

Engelsma MY, Way K, Dodge MJ, Voorbergen-Laarman M and others (2013) Detection of novel strains of cyprinid herpesvirus closely related to koi herpesvirus. Dis Aquat Org 107:113-120

Gilad O, Yun S, Zagmutt-Vergara FJ, Leutenegger CM,

Editorial responsibility: Mark Crane,

Geelong, Victoria, Australia
Bercovier H, Hedrick RP (2004) Concentrations of Koi herpesvirus (KHV) in tissues of experimentally-infected Cyprinus carpio koi as assessed by real-time TaqMan PCR. Dis Aquat Org 60:179-187

Haenen O, Hedrick R (2006) Koi herpesvirus workshop. Bull Eur Assoc Fish Pathol 26:26-37

> Haenen O, Way K, Stone D, Engelsma M (2014) 'Koi Sleepy Disease' voor het eerst in Nederland aangetoond in koikarpers. Tijdschr Diergeneeskd 139:26-29

> Hedrick RP, Gilad O, Yun S, Spangenberg JV and others (2000) A herpesvirus associated with mass mortality of juvenile and adult koi, a strain of common carp. J Aquat Anim Health 12:44-57

Jung-Schroers V, Adamek M, Teitge F, Hellmann J and others (2015) Another potential carp killer?: carp edema virus disease in Germany. BMC Vet Res 11:114

> Lachish S, Bonsall MB, Lawson B, Cunningham AA, Sheldon BC (2012) Individual and population-level impacts of an emerging poxvirus disease in a wild population of great tits. PLoS ONE 7:e48545

Lewisch E, Gorgoglione B, Way K, El-Matbouli M (2015) Carp edema virus/koi sleepy disease: an emerging disease in Central-East Europe. Transbound Emerg Dis 62: $6-12$

> Miyazaki T, Isshiki T, Katsuyuki H (2005) Histopathological and electron microscopy studies on sleepy disease of koi Cyprinus carpio koi in Japan. Dis Aquat Org 65:197-207

> Ono S, Nagai A, Sugai N (1986) A histopathological study on juvenile colorcarp, Cyprinus carpio, showing edema. Fish Pathol 21:167-175

Oyamatsu T (1996) Study on edema disease of carp. PhD dissertation, Tokyo University of Fisheries (in Japanese)

> Oyamatsu T, Hata N, Yamada K, Sano T, Fukuda H (1997a) An etiological study on mass mortality of cultured colorcarp juveniles showing edema. Fish Pathol 32:81-88

- Rakus K, Ouyang P, Boutier M, Ronsmans M and others (2013) Cyprinid herpesvirus 3: an interesting virus for applied and fundamental research. Vet Res 44:85

Way K, Stone D (2013) Emergence of carp edema virus-like (CEV-like) disease in the UK. CEFAS Finfish News 15: $32-34$

Submitted: December 21, 2015; Accepted: March 22, 2016 Proofs received from author(s): April 28, 2016 